\title{
Light and Phytochrome Involvement in Rosa multiflora Seed Germination
}

\author{
Y oshiko Yambe, Kiyotoshi Takeno, ${ }^{1}$ and Takashi Saito \\ Laboratory of Horticultural Science, Faculty of Agriculture, Tohoku University, Tsutsumidori- \\ Amamiyamachi, Aoba-ku, Sendai 981, Japan
}

\begin{abstract}
Additional index words. macerating enzyme, rose
Abstract. Seed germination percentage of multiflora rose (Rosa multiflora Thunh.) was much higher under continuous white light than in complete darkness. Red light was the most effective in inducing germination, and far-red light was ineffective. Exposure to red light for $1 \mathrm{~min}$ increased germination; this effect was saturated at an exposure of 2 min. The red-light effect was reversed by subsequent exposure to far-red light. The results indicate that rose seeds are positively photoblastic, and that the photoreceptor involved is most likely phytochrome.
\end{abstract}

Rose seed germination has been considered unaffected by light, whereas, seed germination in many other species is induced or inhibited by light (Bewley and Black, 1982). Even if germination of rose seeds is influenced by light, detecting significant differences in germination between illuminated seeds and those kept in darkness is difficult, because germination percentages are generally quite low. Therefore, it is still uncertain whether seeds of rose are photoblastic. Leaching achenes with activated charcoal or treating them with macerating enzymes greatly improves seed germination of Rosa multiflora and R. hybrida 'Inspiration' (Yambe et al., 1992; Yambe and Takeno 1992). By using a macerating enzyme to dramatically increase germination potential, we can more definitively examine the influence of light on germination of rose seeds. The present work examined the effect of light on seed germination of $R$. multiflora using achenes treated with Driselase, a common macerating enzyme.

\section{Materials and Methods}

Plant material. Mature cynarrhodia (hips) of $R$. multiflora were harvested at the experimental farm of the Faculty of Agriculture, Tohoku Univ., Sendai, Japan, in Winter 1991-92. The harvested hips were stored at room temperature, and achenes were excised from the hips immediately before use. All experiments were conducted within a few months after harvest of the hips.

Enzyme treatment. The macerating enzyme used was Driselase (Kyowa Hakko Kogyo Co., Tokyo), a product of Basidiomycete fungi with activities as cellulase, pectinase, glucanase, xylanase, amylase, and others. The enzyme preparation was dissolved in 10 mM 2-(N-morpholino) ethansulfonic acid buffer ( $\mathrm{pH} 5.0)$ at $1 \%(\mathrm{w} /$ v). Fifty achenes were placed in a test tube containing $10 \mathrm{ml}$ of enzyme solution. The dry achenes were placed in tubes wrapped with aluminum foil to prevent exposure to light before the start of imbibition. The tubes were rotated at $5 \mathrm{rpm}$ on a rotary incubator at $30 \mathrm{C}$ for $36 \mathrm{~h}$. After enzyme treatment, the achenes were washed with distilled water to remove the enzyme. The achenes were then placed on filter paper in a 9-cm petri dish containing $4 \mathrm{ml}$ distilled water. Three replicate dishes, with 50 achenes each, were used for each experimental lot. All the procedures after incubation in the

Received for publication 12 Sept. 1994. Accepted for publication 28 Mar. 1995. The cost of publishing this paper was defrayed in part by the payment of page charges. Under postal regulations, this paper therefore must be hereby marked advertisement solely to indicate this fact.

'To whom reprint requests should be addressed. Present address: Laboratory of Horticultural Science, School of Agricultural Sciences, Nagoya Univ., Chikusa, Nagoya 464-01, Japan. enzyme solution were done in complete darkness.

Light treatment. The achenes treated with the enzyme were immediately exposed to light for various lengths of time. White light was provided by cool white fluorescent tubes (20W FL20SW; Toshiba, Tokyo). Red and blue light were provided by combining a sheet of red and blue cellophane, respectively, and white fluorescent tubes. Far-red light was provided by combining sheets of blue and red cellophane and incandescent lamps (110V/110W; Toshiba) and a water layer ( $3 \mathrm{~cm}$ deep) as a heat-cut filter. Optical characteristics of the cellophane sheets used are shown in Fig. 1. The intensity of the light used in each experiment is described in the text. After the light treatment, the dishes were wrapped with aluminum foil and a light-proof plastic sheet and incubated at $25 \mathrm{C}$ in darkness until germination percentage was determined. Each experiment was repeated at least twice.

\section{Results and Discussion}

Germination percentage was $>60 \%$ under light, whereas germination in darkness was negligible (Fig. 2). These results clearly indicate that seeds of $R$. multiflora are positively photoblastic. Preliminary experiments with seeds of $R$. hybrida 'Inspiration' resulted in a similar conclusion (data not presented).

Red-light exposure resulted in the highest germination percentages (Fig. 3). Less than $10 \%$ of the seeds germinated in darkness. Germination percentages in the achenes exposed to far-red and blue light were similar to those for achenes maintained in darkness.

Exposure to red light for $1 \mathrm{~min}$ induced significantly higher germination than in the control; this effect was saturated at an

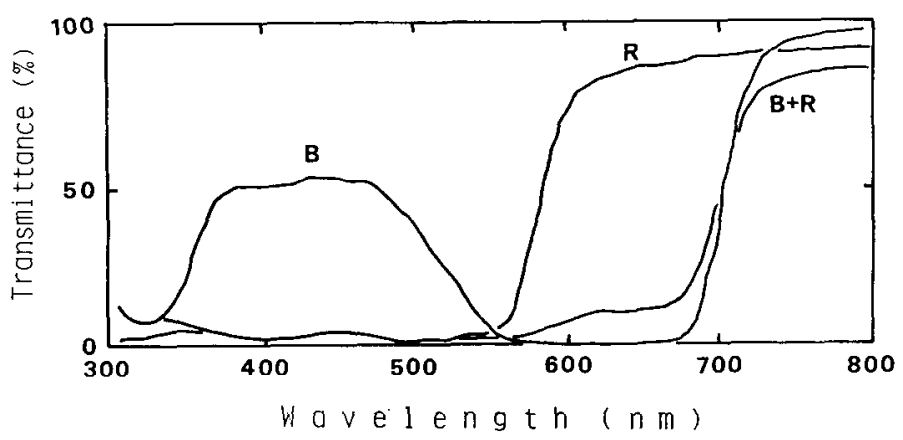

Fig. 1. Transmittance through the cellophane sheets used in the germination experiments. Blue(B) and red(R) cellophane sheets were used with a fluorescent lamp and a combination of blue and red cellophane sheets $(B+R)$ was used with incandescent lamp and a water layer to provide blue, red, and far-red light, respectively (Wada, 1990). 


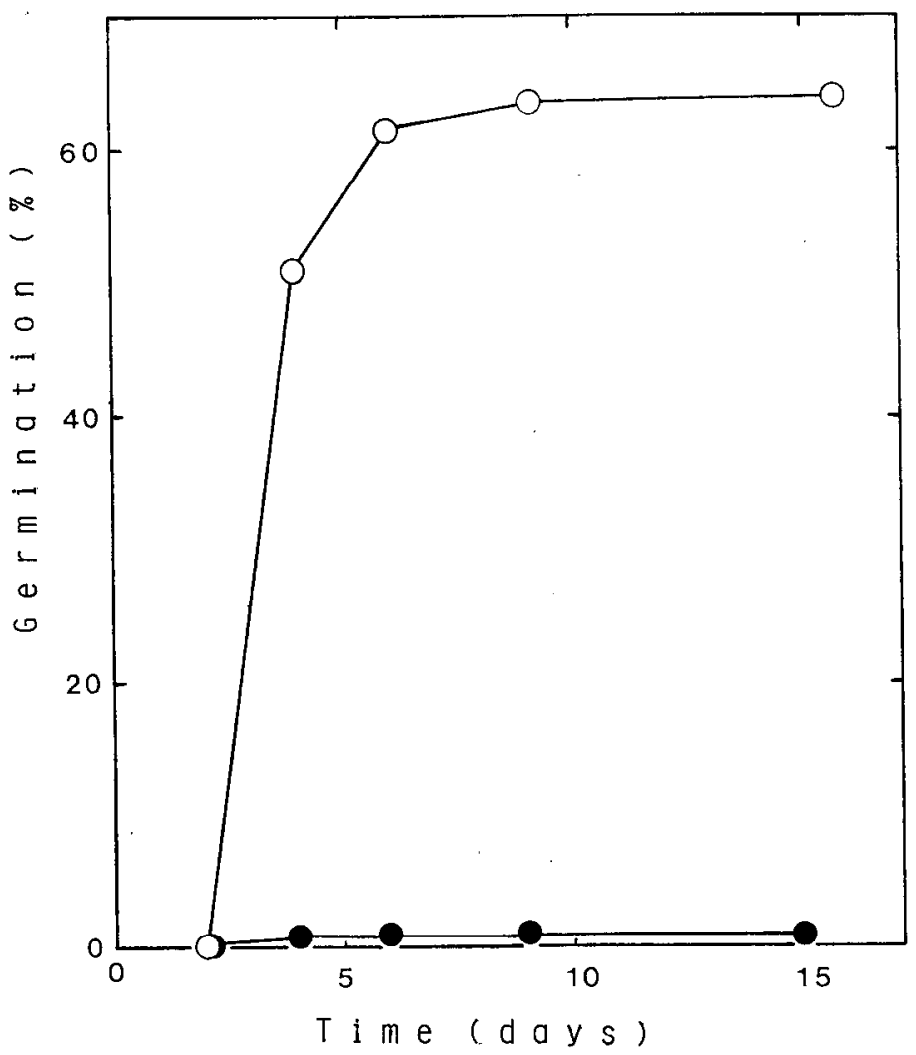

Fig. 2. Effect of light on seed germination of enzyme-treated achenes of Rosa multiflora. Achenes were treated with Driselase under continuous white light or in total darkness for $36 \mathrm{~h}$. After treatment under light, seeds were placed in petri dishes and incubated at $25 \mathrm{C}$ under continuous white light $\left(2 \mathrm{~W} \cdot \mathrm{m}^{-2}\right)(\mathrm{O})$. Achenes treated in darkness were placed in petri dishes and incubated at $25 \mathrm{C}$ in total darkness ( ). Number of achenes used was 150 in each experimental lot.

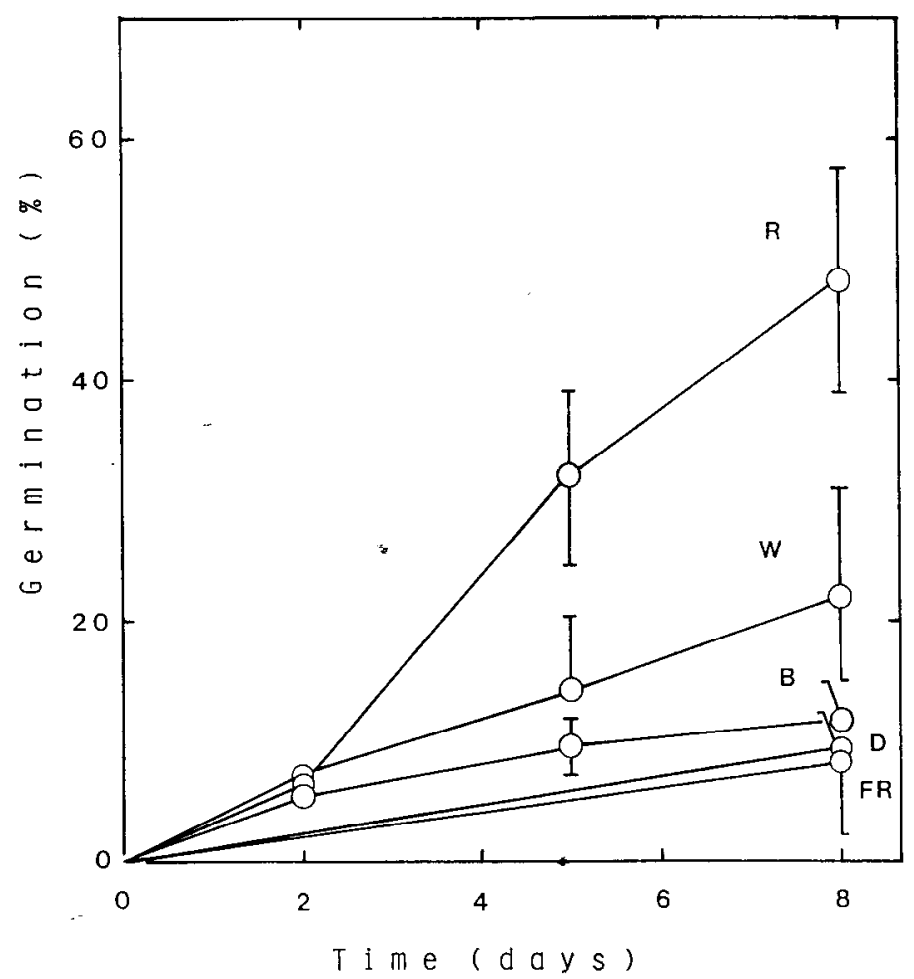

Fig. 3. Effect of exposure to light of different wave-lengths on seed germination of Rosa rnultiflora. Achenes previously treated with Driselase in darkness were exposed to continuouswhite (W), red (R), far-red (FR), or blue (B) light $\left(2 \mathrm{~W} \cdot \mathrm{m}^{-2}\right.$ in all cases except FR, which was $15 \mathrm{~W} \cdot \mathrm{m}^{-2}$ ) or maintained in total darkness (D). Values are means \pm SE of three dishes each containing 50 achencs. exposure of $2 \mathrm{~min}$ (Fig. 4). This result indicates that seeds of $R$. multiflora are quite sensitive to light. In preliminary experiments in which germination tests were conducted after preparing achenes in light, we could not detect any influence of light on rose seed germination (data not presented). The brief exposure to room light during achene preparation may have triggered germination even if the seeds were thereafter incubated in darkness. This may explain why rose seeds have been considered nonphotoblastic.

Far-red light exposure immediately after red light decreased percentage germination to the same level as in darkness (Table 1). The inhibitory effect of far-red light was reversed by a second exposure to red light. The second exposure to red light completely reversed the inhibitory effect of far-red light, even if the exposure to far-red light was as long as $90 \mathrm{~min}$. Because red light was the most effective in inducing germination (Fig. 3) and its effect was reversed by far-red light (Table 1), the photoreceptor involved is most likely phytochrome as first established in lettuce seeds (Borthwick et al., 1952).

Exposure to blue light for a short period of time resulted in a slight promotion of seed germination over the dark control (Table 1). Red-light exposure immediately after blue light resulted in about the same percentage germination as exposure to red light alone. The effect of blue light was similar to that of far-red light (Fig. 3), and the effect of blue light was obscured by subsequent red light (Table 1), as previously reported (Borthwick et al., 1954; Yaniv and Mancinelli, 1968). Taken together, these results indicate that blue light was absorbed by phytochrome (Malcoste et al., 1972). Blue light is absorbed not only by Pfr but also by the Pr form of phytochrome. Thus, blue light absorbed by Pr may be responsible for the increase in seed germination over that in total darkness (Table 1).

The experiment described in Fig. 2 was conducted soon after

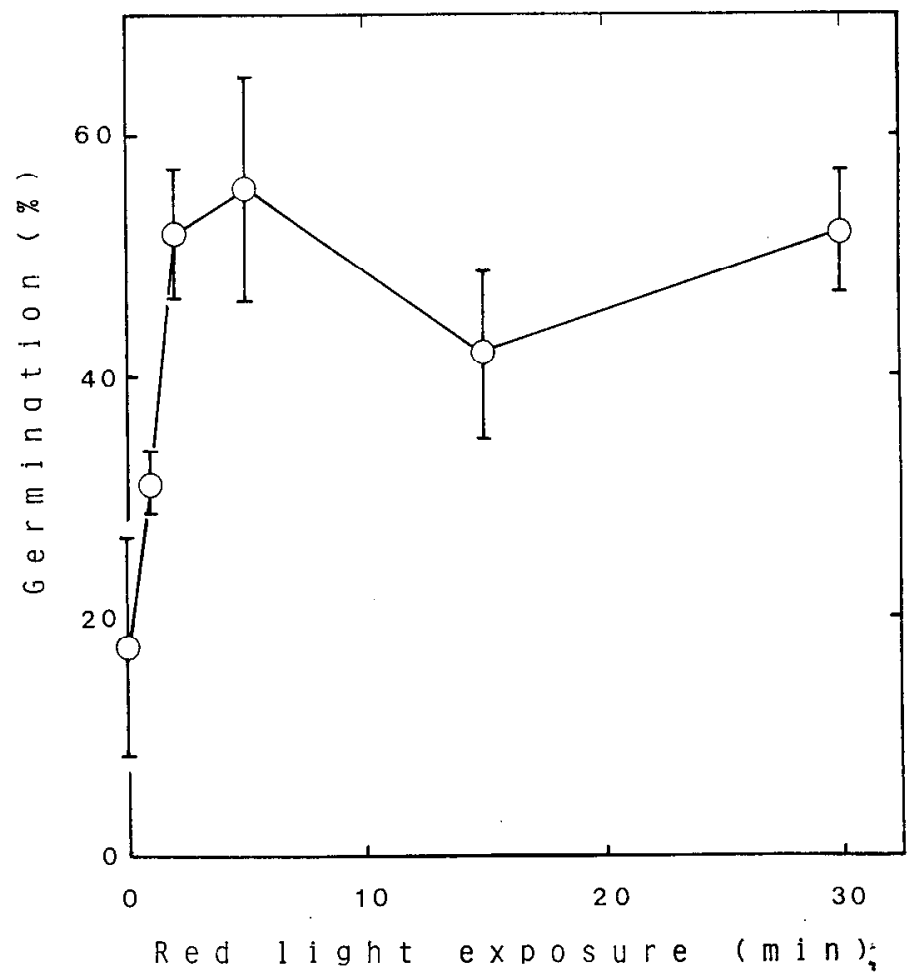

Fig. 4. Relationship between tune of exposure to red light and seed germination of Rosa multiflora. Achenes treated with Driselase in darkness were exposed to red light $\left(5 \mathrm{~W} \cdot \mathrm{m}^{-2}\right)$ for particular periods of time followed by the incubation in total darkness. Germination was recorded 8 days after light treatment. Values are means + SE of three dishes each containing 50 achenes. 
Table 1. Effect of exposure to red, far-red and blue light on seed germination of Rosa multiflora. The achenes treated with Driselase in darkness were exposed to red $\left(\mathrm{R} ; 5 \mathrm{~W} \cdot \mathrm{m}^{-2}\right)$, far-red $\left(\mathrm{FR} ; 15 \mathrm{~W} \cdot \mathrm{m}^{-2}\right)$, or blue $\left(\mathrm{B} ; 5 \mathrm{~W} \cdot \mathrm{m}^{-2}\right)$ light for the particular lengths of time, as indicated in parentheses, and then maintained in darkness. Achenes maintained in total darkness (dark) served as the control. Percentage germination was recorded 8 days after light treatment. Values are means \pm SE of three dishes each containing 50 achenes.

\begin{tabular}{lc}
\hline \hline $\begin{array}{l}\text { Light } \\
\text { treatment }\end{array}$ & $\begin{array}{c}\text { Germination } \\
(\%)\end{array}$ \\
\hline Dark & $13.2 \pm 5.9$ \\
R (30 min) & $62.8 \pm 14.8$ \\
R (30 min)-FR (30 min) & $17.6 \pm 2.3$ \\
R (30 min)-FR (30 min)-R (30 min) & $44.0 \pm 12.1$ \\
R (30 min)-FR (60 min)-R (30 min) & $59.5 \pm 8.4$ \\
R (30 min)-FR (90 min)-R (30 min) & $62.5 \pm 8.3$ \\
B (30 min) & $31.3 \pm 13.0$ \\
B (30 min)-R (30 min) & $54.1 \pm 7.7$ \\
B (30 min)-R (60 min) & $53.4 \pm 12.6$ \\
B (30 min)-R (120 min) & $58.7 \pm 9.9$ \\
\hline
\end{tabular}

the hips were harvested, whereas the other experiments (Figs. 3 and 4, Table 1) were conducted a few months thereafter. Almost no germination was observed in darkness in the early experiment (Fig. 2), whereas about $10 \%$ or more seeds germinated in darkness in the later experiments, namely in the experiments with older achenes (Figs. 3 and 4, Table 1). This fact suggests that $R$. multiflora seeds are strictly photoblastic immediately after harvest, but this may change as the achenes age as occurs in Eragrostis ferruginea (Fujii and Ishikawa, 1962). Generally, seed germination percentage is low and germination occurs sporadically in roses. Seed germination after prolonged incubation could occur irrespective of light condition. This may at least partially explain why rose seeds have been considered nonphotoblastic.

\section{Literature Cited}

Bewley, J.D. and M. Black. 1982. Physiology and biochemistry of seeds in relation to germination. vol. 2. Springer-Verlag, Berlin.

Borthwick, H.A., S.B. Hendricks, M.W. Parker, E.H. Tool, and V.K. Tool. 1952. A reversible photoreaction controlling seed germination. Proc. Natl. Acad. Sci. USA. 38:662-666.

Borthwick, H.A., S.B. Hendricks, E.H. Tool, and V.K. Tool. 1954. Action of light on lettuce seed germination. Bot. Gaz. 115:205-225.

Fujii, T. and S. Ishikawa. 1962. Effects of after ripening on photoperiodic control of seed germination in Erugrostis ferruginea Beauv. Bot. Mag. Tokyo 75:296-301.

Malcoste, R., H. Tzanni, R. Jacques, and P. Rollin. 1972. The influence of blue light on dark germinating seeds of Nemophila insignis. Planta 103:24-34.

Wada, K. 1990. Development, p. 76-85. In: Dept. of Agronomy, Fac. of Agr., Tohoku Univ. (ed.). Guide to experiments in agricultural sciences. Soft Science Publ., Tokyo. (in Japanese).

Yambe, Y., Y. Hori, and K. Takeno. 1992. Levels of endogenous abscisic acid in rose achenes and leaching with activated charcoal to improve seed germination. J. Jpn. Soc. Hort. Sci. 61:383-387.

Yambe, Y. and K. Takeno. 1992. Improvement of rose achene germination by treatment with macerating enzymes. HortScience 27: 1018 1020.

Yaniv, Z. and A.L. Mancinelli. 1968. Phytochrome and seedgermination. IV. Action of light sources with different spectral energy distribution on the germination of tomato seeds. Plant Physiol. 43: 117-1 20. 